\title{
AC 2011-1831: INTRODUCING INTERDISCIPLINARY CONTENT THROUGH ELECTIVES
}

\section{Joseph J. Biernacki, Tennessee Technological University}

Joseph J. Biernacki is Professor of Chemical Engineering at Tennessee Technological University (TTU). His research interests include the kinetics, characterization and modeling of inorganic hydration reactions and their hydrate products as well as the pedagogy of critical thinking, problem solving, team training and how engineering students learn. Biernacki received his BS in Chemical Engineering from Case Western Reserve University and his MS and DRE (Doctor of Engineering) degrees from Cleveland State University.

\section{Christopher D. Wilson, Tennessee Technological University}

Christopher D. Wilson is Associate Professor of Mechanical Engineering at Tennessee Technological University (TTU). His research interests include the mechanical behavior of materials, especially plasticity and fracture of metals. His teaching interests include machine design, finite element method and mechanical behavior of materials. His educational interests include problem solving, active student learning, and teaming. Wilson received his BS and MS in Mechanical Engineering from TTU, his MS in Mathematics from University of Alabama-Huntsville, and his $\mathrm{PhD}$ in Engineering Science from University of Tennessee Knoxville. 


\title{
Introducing Interdisciplinary Content through Electives
}

\begin{abstract}
The introduction of true interdisciplinary content into the engineering curriculum has been among the most debated and difficult to implement requirements of the current ABET accreditation criteria. While most programs use soft activities such as role playing scenarios in capstone courses and similar interdisciplinary simulations, it is possible to design effective coursework with true interdisciplinary interaction. For over ten years the authors, faculty of Chemical (CHE), Electrical and Computer (ECE) and Mechanical Engineering (ME), have been teaching various courses including a CHE-ME elective entitled, "Interdisciplinary Studies in Ceramic Materials Processing," and a CHE-ECE-ME elective entitled, "Introduction to Microelectromechanical Systems (MEMS). Designed with more than one pedagogical focus, these courses were implemented not only to provide real interdisciplinary team-based activities, but also to be true design experiences with either laboratory and computational experiences or both. Over the past ten years, this pair of courses have been test-beds for examining the effectiveness of various team selection strategies, the integration of inquiry-based learning, and even the introduction of a novel inter university collaboration on entrepreneurship. These two experiments in interdisciplinary instruction provided many valuable clues about how students learn in such environments and about how instructors must adapt to an interdisciplinary teamteaching culture. During trying fiscal times, such experiments may be difficult to start or sustain, however, the student experience is always worth the effort.
\end{abstract}

\section{Introduction}

It is helpful to understand what interdisciplinary studies or what interdisciplinarity is. Interdisciplinarity is possibly best described through the fact that many systems, both those found in nature and those invented by mankind, are complex, that is, they cannot be described by a single discipline. Examples of this include the processes that are responsible for life, weather patterns on Earth, the behavior of the new globalized economy, and the mechanics of quasibrittle composites such as portland cement concrete. While vastly different, each of these examples is extremely complex and requires insights from many disciplines to understand, even, in some cases, to have a superficial understanding. Therefore, interdisciplinarity and complexity are intimately intertwined ${ }^{1}$. So, does this imply that $21^{\text {st }}$ Century medical doctors, scientists, business professionals and engineers must be "jacks of all trades?" The answer to this is "no," but rather, they must be trained to recognize interdisciplinary problems, to approach them appropriately and to work in an interdisciplinary environment.

The maturation of well developed disciplinary studies such as economics, sociology, biology, mathematics, physics, chemistry and medicine, etc. was followed by a large number of hybrid 
programs of studies: biochemistry, agribusiness, engineering management, etc. We are now looking at a reintegration of sorts; not a fusion of subject matters to form super-disciplines but rather the refinement of processes that bring disciplines together in ways that create synergistic outcomes which drive our understanding of increasingly complex sociological, economic and technological codependences. It will likely come as a surprise, that organized interdisciplinary programs of study are traceable to the early $20^{\text {th }}$ Century in the origins of the general education curriculum movement ${ }^{1}$. Today, most major universities have degree granting programs in Interdisciplinary Studies and the topic has taken a front-line position in science and engineering research in the US with the introduction of the Science and Technology Centers (STC) and Engineering Research Centers (ERC) by the National Science Foundation (NSF) in 1980's. The preponderance of such centers in research education is clearly articulated by Schuler, who states that at some schools "interdisciplinary programs and centers... have become as numerous as the traditional academic departments ${ }^{2}$." Finally, in 1998 ABET introduced its Engineering Criteria 2000, which mandates that "Engineering programs will demonstrate that their graduates can function on interdisciplinary teams." It turns out that interdisciplinary studies in engineering education is rather "late into the game," in the historical scheme of things.

It is notable to mention that interdisciplinary studies, outside of engineering education, have been very well characterized by educational theorists ${ }^{3}$ and economists ${ }^{4}$ and entire textbooks exist for the training of students ${ }^{5}$. And, while the general education community has been vibrantly embracing interdisciplinary studies for decades, what has the engineering education community been doing? If one measures our interest in a subject in terms of the number of publications on the topic, then one might suggest that we are doing next to nothing. Surely, every undergraduate program in the country that desires to be accredited by ABET is doing enough to satisfy program reviewers. An admittedly incomplete search of papers on engineering education topics uncovered a handful of citations dating back to about the year 2000, surely no coincidence, and even fewer dating to just prior to that time. Among these, Muscat, et $\mathrm{al}^{6}$ describes a true interdisciplinary course on semiconductor processing at San Jose State University, which is quite similar to the MEMS course describe here by the authors. O'Connor, et al. ${ }^{7}$ also describes a true interdisciplinary experience involving physics and electrical engineering students. At Bucknell University, Shooter and $\mathrm{McNeil}^{8}$ offer a course cross-listed between mechanical and electrical engineering and Biernacki and Ayers ${ }^{9}$ describe a vertically and horizontally integrated course that includes civil and chemical engineering students. In a broad attempt to impact large numbers of students with an interdisciplinary infrastructure, the University of Texas has established the NANOLAB ${ }^{10}$ as a cross-cutting entity for use by multiple disciplines within the university at large. And, while others exit, these represent a range of possibilities. Notably, while most of those mentioned offer some discussion concerning how students are assessed, and all demonstrate that students are meeting some required rubric, none assess the efficacy of the interdisciplinary training on learning, and in general, few can say little regarding whether or not students are obtaining an improvement in team training as compared to any National norm. 


\section{Background}

Tennessee Technological University (TTU) has about 11,000 students, its College of Engineering (COE) includes roughly 1900 of the undergraduates. The COE has degree granting programs in Chemical (CHE), Civil and Environmental (CEE), Electrical and Computer (ECE), Industrial and Systems (ISE), and Mechanical Engineering (ME), Mechanical and Industrial Technology (MIT) and Computer Science (CS). The BS, MS and PhD are conferred. Entering freshmen can declare a major immediately or enter through the non-degree granting Basic Engineering (BE) program. Some engineering students are required to take a freshman Basic Engineering course entitled, "Introduction to Engineering” which includes a good introduction to teamwork $^{11}$. While the student body in Introduction to Engineering is interdisciplinary, the emphasis is largely on teamwork and does not focus on the interdisciplinary element per se.

Each of the COE engineering units requires a senior-level capstone design course. Consistent with the majority of engineering programs around the country, the capstone courses are administered by the departments and so are discipline-homogeneous, the interdisciplinary teamwork element in most cases coming from teamwork incorporating intradisciplinary specialization. In addition to this form of contrived "interdisciplinary" teamwork, CHE and ME and CHE, ME and ECE jointly offer two electives that are truly interdisciplinary, "Interdisciplinary Studies in Ceramic Materials Processing," and "Introduction to Microelectromechanical Systems (MEMS).” These two courses were developed as a direct reflection of the faculty research interests and desire to train their students in interdisciplinary environments. The ceramics processing course was also initiated with the help of a grant from the National Science Foundation (NSF) ${ }^{12}$.

Materials topics are inherently interdisciplinary and, in a way, Materials Science is an interdisciplinary program, a fusion of chemistry, physics, mathematics and engineering. The processing of materials involves chemical and physical changes that transform raw materials into materials products. Those products, typically solids, may be characterized, chemically, mechanically, electrically, and optically and, furthermore, specification must be developed for their use in structural and non-structural, and static and dynamic environments. To take raw materials and produce material products is a daunting challenge, even for interdisciplinary teams.

MEMS also are inherently interdisciplinary; even the name, microelectromechanical systems, is interdisciplinary. Unfortunately, the name implies a mechanical-electrical fusion whereas in fact, microchemoelectromechanical systems (MCEMS) would be a more suitable name since many devices now involve chemical sensing as well as mechanical structures integrated with electronic devices. Like materials topics, MEMS are a rich platform and opportunity for introducing interdisciplinary team-based coursework. 


\section{Interdisciplinary studies in ceramic materials processing}

Interdisciplinary studies in ceramic materials processing is open to all engineering, technology, math and science majors, however, historically has exclusively attracted chemical and mechanical engineering students. The course is offered at the 4000 (senior level undergraduate) and 5000 level (introductory level graduate) and generally includes two or more graduate students out of a class of nominally ten. The student body is typically split 50/50 CHE/ME and generally makes it simple to form well balanced interdisciplinary teams. The course has been offered once yearly since 1998. Originally offered as a $3 \mathrm{cr}$ hr "lecture," it was never presented as strictly a classroom course and the faculty have always utilized a portion of classroom time for discussion, student presentations, workshop activities and laboratory research. In 2006 it was officially changed to 2 cr hr "lecture" plus 1 cr hr "laboratory," mostly for administrative purposes and because it better reflects the distribution of what actually takes place.

The course content has been detailed elsewhere ${ }^{13}$, but is summarized here. There are five major elements of the course:

1. Faculty led presentations - The course is not a "materials science" class and so does not cover classical material science topics such as the structure of matter. Rather, it is focused on processing and characterization of materials products. Therefore, the faculty lead presentations include: raw materials, beneficiation, milling, mixing, forming and firing (sintering), microscopy and associated micro analytical techniques, $\mathrm{x}$-ray diffraction, strength and failure of brittle materials, hardness and fracture toughness concepts and test methods.

2. Faculty led activities - These translate what is learned during faculty lead presentations into mini-lab assignments. These have included some, but not typically all of the following activities in any given term: mixing lab, forming lab (always done), electron microscopy (always done), x-ray diffraction, and strength testing (always done).

3. Faculty led skills workshops - Skills workshops focusing on the Scientific Method are typically included as a one or two class period discovery-based activity. Most students schooled in the US learn the Scientific Method in grade school, but lose track of it or consider it to be something for grade school science projects, not for the real world and not for engineers. The instructors emphasize that discovery is really the application of the Scientific Method, regardless what age or discipline. In addition, a workshop on team formation is generally conducted, wherein teams are formed. The interdisciplinary nature of the subject matter is emphasized and since the class size is very small, teams are generally formed based on common interest in a particular project concept or simply by paring ME and CHE students at random. At this point, all students have received 
repetitive team training during their undergraduate course of student in both CHE and ME.

4. Student led presentations - The instructors use "The New Science of Strong Materials Or Why We Don't Fall Through the Floor,” by J. E. Gordon as a reading activity, from which each student must summarize and present on one chapter. Presentations are to be 15 minutes followed by questions.

5. Open laboratory - Used to give student teams the opportunity to work on their term projects while the faculty are present, the open lab is a time when the instructor can observe team performance and likewise interact with them. Open lab time increases as the term progresses.

The focal point of the course is an interdisciplinary materials design term project and everything done in the course prepares the students to be able to assimilate information from the literature, propose a material synthesis, process a prototype and characterize it. The term project has take on many incarnations over the years, all of which have been effective experiences as measured by student performance on exams and assessment of the final project learning outcomes. Some, however, have been more effective than others in terms of producing an actual product, something that is satisfying for students and produces feedback that fuels their inquiry. Some of the concepts are listed here with a bit of commentary:

1. A single product was developed by the entire class, each team was responsible for one part of the entire process. This turns out to be quite difficult to achieve in one term, about 15 weeks, since too many of the tasks are sequential in the production of a ceramic material, e.g. forming must be complete before firing can be done. While achievable, it is awkward and somewhat unsatisfying to the student body. Students express frustration particularly if they are at the end of the processing chain. At the same time, students realize a rich real world team experience wherein some tasks are indeed sequential. Sequencing is mentioned by Brannick ${ }^{14}$ as one of two key features of teamwork that must be performed well if the team is to be effective. So, while this approach makes it a challenge to produce a final product, and will likely frustrate some students, it might be used in an environment wherein the instructor wants to emphasize the sequential nature of teamwork. From an assessment perspective, students learn the course material, but some might not produce as complete a project as they would like, e.g. those at the end of the production sequence.

2. A research based topic is emphasized. In this case, students must find a current topic in ceramic materials processing, propose a mini-thesis and conduct their study. Each team is independent and works toward their objectives and goals. This works well and outcomes are only dependent upon the effort that the students put into the work. In many ways it lacks the dynamic environment of the "single project" concept described above. 
3. A product driven topic is emphasized. This is the most recent rendition which focuses on selection of a commercial product and then proposing and producing a prototype that can compete with the commercial product. Use of recycled glass to make glass ceramic floor tiles and production of a ceramic water filter using waste terra cotta are two example projects. Within this theme, the instructors have introduced additional interdisciplinary concept requirements including environmental impacts (students must use some form of waste material and quantify the impact that their production process would have on waste mitigation), and economic analysis (students must do a cost and market analysis to see if their product can compete).

\section{Introduction to microelectromechanical systems}

Introduction to MEMS is a $3 \mathrm{cr}$ hr course open to all engineering, math, and science majors and, like ceramics processing, is offered at the 4000 and 5000 level. The course is typically populated by three to five CHE, 10-15 ME and 10-15 ECE students, 25 is a nominal class size. The course has been offered since 1999 and is always taught by one CHE and one ME faculty and at least one ECE faculty. As many as four instructors have been involved in a single offering of the course. Guest lecturers are frequently invited to provide anywhere between one to three class sessions on special topics of interest that term.

Like ceramics processing, the course revolves around the interdisciplinary team term project. In this case, the term project must involve device design and computational assessment. Since there is no MEMS fabrication facility at TTU, there has never been a fabrication requirement of the project, however, team designs have been fabricated off campus outside of the scope of the course and those devices used as prototypes for lab activities in subsequent years. Some projects have also nucleated MS and PhD dissertation research ${ }^{15,16,17}$ and have involved the interdisciplinary faculty team as co-advisors or committee members. Some of this research went beyond campus to a DOE National Lab.

The course content is delivered in five concurrent streams:

Faculty led lectures - Classroom lectures are delivered by the faculty on content that includes: fabrication, relevant semiconductor fundamentals, micro-fluidics (both pressure driven and electro hydrodynamic), diffusion, reaction and mixing in micro-flows, and mechanics of microscale structures.

Faculty or guest led case studies - Case studies in the design and analysis of devices have proven to be invaluable tools for training student design teams. The typical undergraduate or entry level graduate student has been through a program that teaches them to scale-up and to work with macroscopic systems, e.g. internal combustion engine, refinery, computer circuit in a television 
or radio, etc., but will have no intuition or experience that will enable them to make good engineering judgments about micro-scale device design. Numerous case studies are typically used on a wide variety of devices including lab on a chip, cantilever-based sensors and electrooptical devices. Some of these have been based on the faculties' own research ${ }^{18,19,20,21,22 .}$

Faculty led computational workshops - Computational design tools are an essential element of micro-scale device design and are highly interdisciplinary in nature. A series of workshops are led during the first half of the term that introduce students to the use of various software packages (use your favorite) that can handle micro-scale multi-physical phenomena. Several team and individual assignments are used as templates from which student design teams can then develop models for their term project.

Faculty led skills workshops - The skills workshops for MEMS focus primarily on interdisciplinary design topics. As with any complex system, the MEMS device design is multifacetted and fusing the interdisciplinary contribution of team members is a difficult challenge for students that have never been placed in such a situation. During these workshops, the instructor leads an inquiry-based activity that enables student teams to develop a working model of the MEMS design methodology. While it is possible to find such models (schema) in the literature or text books, it is better to have student teams members react to questions regarding the design process and to develop their own schema. As a way of validating student concepts, they should then be compared to other widely accepted resources. These workshops are frequently combined with small team or individual assignments such as writing a news article on the interdisciplinary nature of MEMS. The news article assignment is a favorite with the faculty since it can be assigned at the very beginning of the term as a way to enable students to consider what interdisciplinarity is and how it relates to the study of MEMS design.

Open laboratories - Laboratories in this case are open sessions for student teams to meet with the faculty and for faculty to observe student team behaviors. Student teams may choose to discuss any element of their project with faculty mentors or the faculty may choose for an open session to focus on some milestone activity, e.g. preliminary design concept, computational model for the device, etc.

The team project is always to invent and design a MEMS device and to predict its performance using computational tools. Fabrication files are sometime required, particularly if post-course fabrication is anticipated. The design goals have either been arbitrary, i.e. any type of device is acceptable, or targeted, i.e. a course theme is chosen which dictates an application or class of device. In 2005 a Homeland Security theme was used. The theme-based approach is particularly attractive because it motivates the students by providing an ultimate application. The Homeland Security theme was also used to pilot a novel interdisciplinary collaboration with a colleague at 
Vanderbilt University's Peabody College, the result of which has been published under the cover Entrepreneurs in Action ${ }^{23}$.

\section{Attracting students to the elective}

Engineering students have many elective options both from within the COE and from the campus at large, e.g. advanced analytical chemistry, advanced mathematics, biology, etc. In this environment, how are students attracted to options like MEMS or Ceramic Materials Processing? During the first few years in which each course was offered, the instructors distributed e-fliers to all eligible students within the COE and the College of Arts and Sciences. The e-fliers, also posted at the instructor's website, provided an exciting description of the course, who should take it and a brief outline of the course content and requirements. The highly specialized nature of both courses inherently limits the enrollment. Ceramics, in particular, attracts only ten or 12 students each term, just enough to keep it viable at TTU. MEMS draws more students because it is a more universally applicable field of study with many undergraduates and graduate students interested in the breadth of applications.

Once established, the instructors have used e-fliers when significant changes to the course were being implemented, e.g. many chemical engineering students are now interested in biological applications since a Biomolecular option is now available in the Department of Chemical Engineering at TTU. Recent offerings of the ceramic materials course have included the option to investigate bio-compatible materials applications for students specifically interested in bioapplications. Similarly, more bio-emphasis has been included in recent MEMS offerings and are now included in the current e-fliers for student recruiting.

There is a great deal of competition for students in technical elective courses. These interdisciplinary courses compete with electives that are wholly within a given major. These traditional electives are seen by some students and most faculty as the "tried and true" choices. The prerequisites to these tried and true courses are typically junior level offerings within a major that are not broadly taken by students outside of that discipline. On the other hand, the interdisciplinary courses described here have been carefully crafted to use only lower division math, science and engineering courses as common prerequisites. However, the faculty does take advantage of the upper division courses the students have taken. In some instances, the students actually guide their teammates through the brief details of the discipline-specific courses in justin-time exercises. This allows the students to act as experts in their own disciplines-a situation that is hard to achieve in the discipline-specific technical elective. This situation, coupled with team leadership opportunities, entices the adventurous student to take the interdisciplinary course.

\section{Interdisciplinary co-teaching}


Both courses are taught by interdisciplinary teams of instructors, one CHE and one ME faculty for Ceramics Processing and at least one each CHE, ME and ECE for MEMS. This has created some unique faculty team coordination challenges and some unique responses from students. The approach in the two courses has been, however, somewhat different and so they are treated separately below. Teaching credit is simply split by dividing the course credit hours by the number of faculty listed as instructors of record.

\section{The ceramics faculty team}

Ceramics Processing has been taught by the same two instructors since its inception. Both faculty are present for most class and lab sessions unless one or the other is traveling. Travel schedules have never required both to be gone at the same time and the faculty is jointly present more than $80 \%$ of the time. The two faculty work as a team during class and lab and have coordinated their presentations to seem as though it is one faculty teaching not two. This requires a unique duo that truly embraces the interdisciplinary content and nature of the course and is something that would need to be cultivated by most faculty at large. The use of both faculties' time in this way may be questionable; however, our experience is that a unified, joint front must be presented to emphasize the interdisciplinary teaming. If the faculty do not present themselves as a team, the students will detect this. If the faculty work and move as a team, it is clear that the students perceive this and will emulate the behavior. As for economic efficiency, if two disciplinary courses were being taught at the same time, splitting the student body, then both faculty would be totally occupied anyway. Let your administrators work it out for themselves; the interdisciplinary environment is worth the investment, if any.

\section{The MEMS faculty team}

The MEMS course traditionally has three faculty teaching, but has utilized as many as four. The aim, of course, is to team teach without "gang” teaching. This creates significant logistical difficulties, coordinating the syllabus content with travel and other teaching commitments of the instructor team. Such must be sorted out so that the course content is delivered in a logical and time sensitive manner so that students are prepared to address the design challenges on-going, in a balanced manner, so as not to push too much of the project off until the end of the term. Achieving this, the more significant challenges involve leadership and teamwork among the faculty that is perceived as interdisciplinary by the students. It is virtually impossible and uneconomical to commit the time of all three or four faculty during every class or lab session, in fact, the faculty simply will not do it. So, this is strike one from a student's perspective. The students tend to perceive absence from class, as inattentiveness to the team-based nature of the course content and objective. The faculty must defuse this by frequently talking with the students, referring to the other faculty members' content during lectures so as to bring the other 
colleagues into the room by virtue of reference and to make interdisciplinary linkages between the present content and previous or future content of the other faculty. This technique must be done deliberately and consciously and requires practice by all of our instructors. In addition, faculty leadership is extremely important. Teams need leadership, Brannick, et al ${ }^{14}$, lists "leadership" as one of seven key behaviors for good team performance. Based on student evaluations, that indicated their lack of perceived organization, our faculty team agreed to rotate course leadership every year. The chosen lead faculty is the focal point for student faculty contact, communicates syllabus related topics to the student body, is responsible for scheduling and literally is the "front man" for the course that term. When handled this way, the role of the other faculty is not diminished; it is simply placed in the context of a team that has visible leadership. Students are familiar with a course with one head, one faculty, one instructor; not a beast with multiple heads all barking orders and setting schedules and sometime biting each other.

\section{Interdisciplinary student teams}

How should we pick students teams so that they perform the best? This seems to be a question that is asked again and again by college-level instructors. Biernacki, has described his experience with teams in some detail elsewhere ${ }^{24}$, but the answer is surely unclear and not well quantified. However, what does appear to be important, is that we, as instructors, must provide a real world environment wherein teams are not chosen because someone is our friend. In this course, as well as in others offered by the authors, teams are chose based on skills and interest, which takes precedent, depends upon the course context and the number of students from which to form teams. Real world team training is absolutely critical. Discussion about teams, what it means to be a team, good and bad team behaviors and how teams will be chosen in industry is important to develop an appreciation for teamwork rather than permitting students to feel that course/lab teams are simulations, e.g. not the real world. The authors emphasize that course teams have a goal and that team members must have the correct skill set to achieve the goals and that team members are co-responsible for the outcomes. The students taking these courses are typically senior level undergraduates or entry level graduate students and most would have been through some formal team training by this point, therefore, formal team training is not an objective of either MEMS or Ceramic Processing. Instead, the faculty lead a one class-period workshop that reaffirms good team practices through a discovery-based activity that requires students to think about what they already know about teams and to place it in the interdisciplinary context of the course. Students are then led through a team forming activity wherein teams of three or four are generally established, depending upon the size and disciplinary distribution of the student body. Because of the interdisciplinary constraints it is not easy to form teams that are optimized based on skills or interest, so we give interest priority over skills since students always vote to work on topics of interest over topics for which they may be best trained. Since student opinion is important, we like to give students a voice in team choice 
at this level in their academic training. A typical session involves discussion of interdisciplinary design followed by some small group work leading to production of a list of device categories. Students are then asked to associate with a device category that they might like to work on after which interdisciplinary lines are drawn and teams formed. With small student numbers and disciplinary constraints we cannot do much better, particularly if we want students to have a voice. Other strategies have been used including faculty appointed teams. It turns out that with such small number of students, even after observing teams for many years, it is impossible to discern if one approach over another produces better teamwork outcomes.

As reported by Biernacki, many students feel that course/lab teams are simulations, not real teams, but rather like play acting. This degenerates the experience and relegates it to the equivalent of a video game. Course/lab teams must be viewed as real world teams with an objective. In fact, the objective of the course team is to get a good grade in the course. To do that, the team must deliver on its goals, this is the real world. The extent to which the team members are concerned about their grade is, however, the factor that motivates them individually and the instructor has little control over that. Students, after all, are not subject to being fired and some would like quite well to ride along on the coat tails of others. This creates opportunity for the introduction of content on ethics, which has been used by Biernacki as well, however, is not generally introduced in the two interdisciplinary courses of interest here.

The interdisciplinary student teams have some unique challenges. Since this might well be the first time that students have worked with an interdisciplinary team on a significantly challenging task, they may find it surprising that disciplines tend to cultivate characteristics. For example, chemical engineers tend to focus on mass and energy balances and view the process in terms of balances; they will, in most cases, be confused about how what they view as a process will in any way integrate with an electronic circuit. The mechanical engineers will want to see machines when they look at their device, if they don't, they might not relate. Likewise, the electrical engineers will want to reduce the process and the machines to electrical circuit components. Such can create stress among the student team since individuals might not see how they fit in, depending upon the choice of device and extent to which it can be visualized as a process, machine or electrical circuit. Having one member feeling rather "left out" frequently happens when the device project is perceived to be weighted towards one or two disciplines. It is the instructors' job to continually enable the team to focus on the interdisciplinary elements, to help the team to discover the connections that they might be missing. Frequent team meetings with the interdisciplinary faculty have been found to be very helpful for building student team confidence and for identifying when teams seem out of balance and one member seems left out and without a role to play. The open lab time is useful here.

\section{Student evaluations of the course}


Student evaluations consist of the IDEA evaluation; a formalized assessment with National norms, used by and required by the University. The IDEA evaluation includes questions related to the following metrics that are used as indicators of course effectiveness as perceived by the students:

1. Learning fundamental principles, generalizations, or theories.

2. Learning to apply course material (to improve thinking, problem solving, and decision making).

3. Acquiring skills in working with others as a member of a team.

Of particular interest is Metric (3), concerning team skills, see Figure 1 for a summary by year. In general, students feel that the MEMS course is providing a better team experience than students at large (Nationally) do when assessing similar courses. While the student numbers are small and the data likely unreliable, it is what one has to work with when dealing with specialized elective courses at relatively small schools. Learning related Metrics (1) and (2) are not as positive and are typically on par with the National norms. Does this mean that interdisciplinary courses are a failure? Not at all, it simply suggests that even when teaming appears to be done correctly, or at least somewhat better than on the National average, that students don't feel that they learned any better. Keep in mind that these findings are by no means statistically significant because of the small student populations. In addition, this is what the students feel, not how well they actually learned.

There is a bit more information to be mined from Figure 1. In 2007 the course was not offered and in 2006 the data was not available, nor prior to 2002 and not as of the publication of this paper for 2010. What happened in 2004 and 2008? In 2008 a fourth faculty was introduced to the mix. And, although that faculty brought a great wealth of experience in the area of MEMS fabrication, it appears that the content and expectations of the course was pushed too far for a single term and the team related experience was neglected. These flaws were very clear to the faculty team; the assessment clearly indicating that the faculty impressions and behaviors are well reflected in the student perceptions as measured by the IDEA assessment tool. Furthermore, the addition of a fourth faculty, clearly complicated course management and that was also apparent to the student body.

What about 2005, which appears to be a good year? In 2005 an ambitious experiment was conducted which merits a paper on its own; only a very brief summary is given here. Our faculty teamed up with a colleague of the Peabody School of Education at Vanderbilt University who was teaching a course on entrepreneurship to business students. The collaboration brought the two student bodies together via “e” communications (e-mail and Internet). Faculty exchanged guest lectures and the business students at Vanderbilt were introduced to MEMS while the engineering students at TTU were introduced to entrepreneurship. The engineering students fed 
relevant device performance information to the business students and likewise the business teams reciprocated with information on the market relevance of the devices. The importance of interdisciplinary interaction was also heightened by more discussion about how engineers would frequently need to interact with others in business or production and that they would likely not have an engineering or science degree, but would probably have totally different motivations and perspective. In the end, it appears that at least form the students' point of view; they feel that their team experience was somewhat better. Again, the outcomes must be approached with caution because of poor statistical confidence.

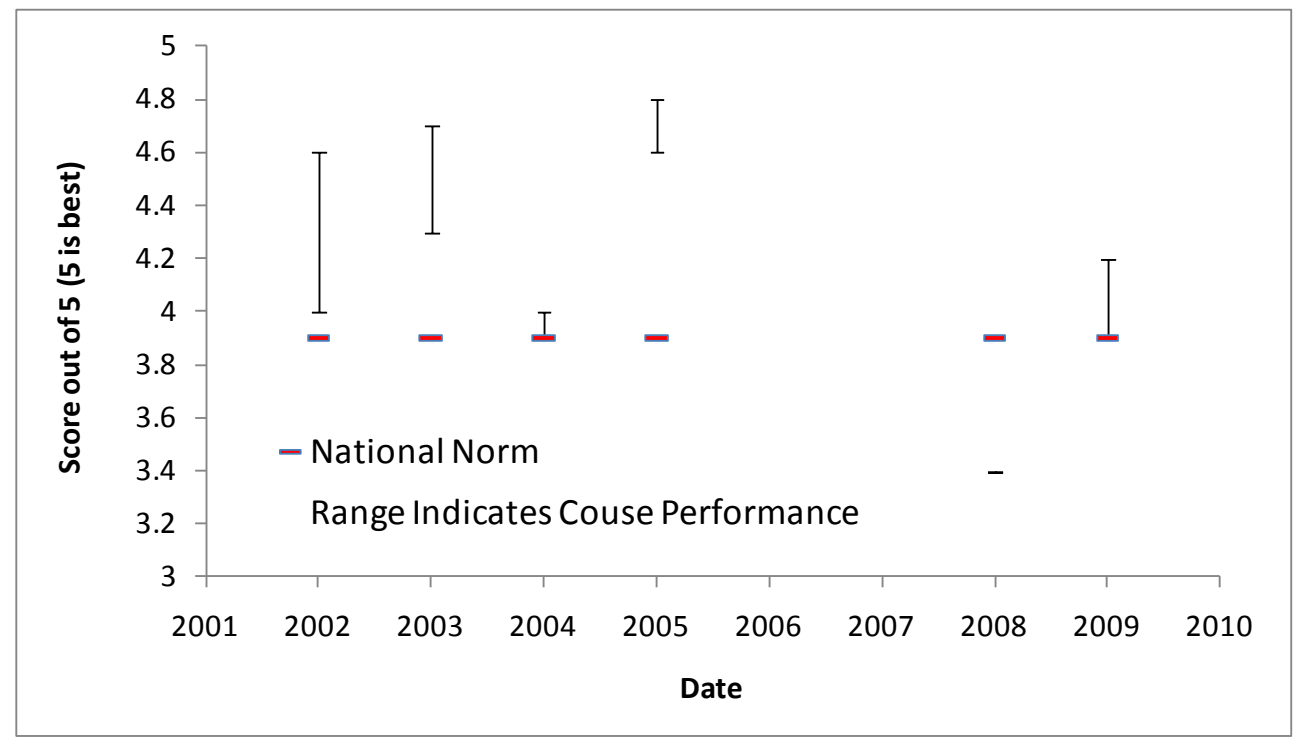

Figure 1. Student response about the MEMS course to questions concerning, "Acquiring skills in working with others as a member of a team.”

While similar data is available for the Ceramics course, student assessment data suggests that their team experience is no better than the National norm average. Why is this, since they are treated more or less the same and the MEMS students feel their experience is better than average in most years? Since there are many factors that make the course content different, it is difficult to say with any degree of certainty. In general, however, team sizes are typically smaller and so it is possible that students do not gain the team experience from teams of two.

\section{Assessment}

In both courses, assessment of student performance is largely based upon the team term project. An obligatory final is used, but typically represents only $10 \%$ of the overall grade. Some individual homework is assigned amounting to $15-20 \%$ of the overall grade. The balance of the final grade is the team related term project. The project is always graded in at least three parts: 
(1) a written proposal, (2) a final written report, and (3) a final oral report. At times an oral proposal is also required and an interim written (brief) or oral report.

Finally, can we tell anything at all about how effectively students learn the material? If measured in terms of successful team project, the answer is likely, no. Most student teams had a very difficult time developing device designs that could be suitably characterized (computationally) in one term. Many had a hard time synthesizing the appropriate engineering knowledge to conduct a complete design project within the constraints of one term. The team training appears to be quite a separate activity from the learning experience when the material is pushing the students to what appears to be the edge of their performance capabilities. In fact, a recent study by Lattuca, et al $^{25}$, suggests that, “despite widespread support for interdisciplinary curricula, there is little evidence that such courses are particularly efficacious or that they are superior to disciplinary courses in promoting student learning.” That said, there are approaches that in fact produced better projects. Students were clearly motivated by the theme challenge concept. Above and beyond anything, the projects improved as the level of coaching increased. Students at the senior and introductory graduate level do not inherently know how to synthesize their disciplinary knowledge into interdisciplinary product. That said, it is quite apparent that student performance varied from year to year as a function of the level of faculty intervention. The effect of the introduction of the fourth instructor on student outcomes is not quantifiable.

\section{Using course outcomes for ABET purposes}

Detailed records were kept so that the course results could be used for ABET reporting. The course outcomes were specified in terms of ABET Criterion 3, shown here for the MEMS course only:

Outcomes: Students must demonstrate... :

1. Criterion 3c - an ability to design microsystems to meet desired needs,

2. Criterion $3 \mathrm{~d}$ - an ability to function on multi-disciplinary teams,

3. Criterion $3 e$ - an ability to identify, formulate, and solve engineering problems related to microsystem technology,

4. Criterion $3 g$ - an ability to communicate effectively, and

5. Criterion $3 \mathrm{k}$ - an ability to use the techniques, skills, and modern engineering tools necessary for engineering practice as they relate to the design, fabrication and performance assessment of microsystem technologies.

Traditional requirements are defined:

Requirements: Students must... :

1. participation in all in-classroom and out-of-classroom activities,

2. complete a team analysis paper and a team design paper,

3. complete individual homework and quizzes, and

4. complete a final exam. 
Assessment: Each requirement was assessed using one or more of the outcome criteria. Table 1 maps the relationship between Outcomes, and Requirements.

Table 1. Mapping of outcomes and course requirements, illustrating which of the requirements was used to assess for which outcome.

\begin{tabular}{|c|c|}
\hline Outcome & Requirement \\
\hline 1 & $2,3,4$ \\
\hline 2 & 2 \\
\hline 3 & $2,3,4$ \\
\hline 4 & 1,2 \\
\hline 5 & 2,4 \\
\hline
\end{tabular}

A more detailed description of this process is presented elsewhere by Biernacki ${ }^{26}$.

\section{Summation}

Two interdisciplinary courses have been taught for more than ten years at TTU, both involve teams of students that cut across either two or three engineering disciplines and utilize a term project as the primary basis for student assessment. One, Ceramic Materials Processing, is a lab oriented course wherein students must design, produce and characterize a material/product. The other, Microelectromechanical Systems, is a device design course in which student must assess device performance computationally/theoretically.

It is very clear that student perceptions require that interdisciplinary teams of faculty must be very well coordinated else students will respond poorly to questions regarding the faculty. If, however, a lead instructor is identified for a faculty team of more than two, it appears that students are less aware of the challenges faced by the instructional team.

It appears that students respond, on average, better than the National norms when asked about their team experience in such interdisciplinary courses, though the data here is for very small student populations and despite the fact that these courses have been taught for many years. Furthermore, nothing can actually be said about the learning effectiveness since nothing notable concerning learning was discernable.

One should, however, ask, are we attempting to improve learning through teamwork, or are we attempting to enable students to become better team members? While both are hopeful outcomes, it appears that this study might suggest that we are producing better team members, at least from the perspective of the student. 


\section{Acknowledgements}

The authors acknowledge financial support from the National Science Foundation (NSF) through grant award No. DUE-9950411.

\section{Bibliography}

${ }^{1}$ Klein, J. T. (2004), “Interdisciplinarity and Complexity: An Evolving Relationship,” E:CO Special Double Issue, 6(1-2) 2-10.

${ }^{2}$ Schuler, R. E. (1994), "Interdisciplinary Centers: A Natural and Necessary Force for Creativity and Change in Engineering Research Education,” Journal of Engineering Education, January 1994, 29-32.

${ }^{3}$ Newell, W. H. (2001), “A Theory of Interdisciplinary Studies,” Issues in Integrative Studies, 19, 1-25.

${ }^{4}$ Szostak, R. (2007), “How and Why to Teach Interdisciplinary Research Practice,” Journal of Research Practice, 3(2), Article M17.

${ }^{5}$ Repko, A. F. (2008), “Interdisciplinary Research-Process and Theory, Sage Publications, Inc., p. 295.

${ }^{6}$ Muscat, A. J., Allen, E. L., Green, E. D. H., and Vanasupa, L. S. (1998), "Interdisciplinary teaching and Learning in a Semiconductor Processing Course,” J. of Eng. Ed., October, 413-421.

${ }^{7}$ O’Connor, T., Sibray, H., and Forinash, K. (2001), “Interdisciplinary Research project Involving Physics and Electrical Engineering Students,” J. Eng. Ed., July, 423-428.

${ }^{8}$ Shooter, S., and McNeill, M. (2002), "Interdisciplinary Collaborative learning in Mechatronics at Bucknell Unversity,” J. Eng. Ed., July, 339-344.

${ }^{9}$ Biernacki, J. J., and Ayers, J. B. (2000), “Teaching Cellular Automaton Concepts Through Interdisciplinary Collaborative Learning,” Chem. Eng. Ed., 34(4), 204-309, 315.

${ }^{10}$ Heitsch, A. T., Ekerdt, J. G., and Korgel, B. A. (2009), "NANOLAB at the University of Texas at Austin: A Model for Interdisciplinary Undergraduate Science and Engineering Education,” Chemical Engineering Education, 43(3), 225-231.

${ }^{11}$ Hunter, K. W., Matson, J. O., and Dunn, R. (2002), “Impact of a Fifty-Minute Experiential Team-Building Program on Design Team Performance," Proceedings of the 2002 American Society for Engineering Education Annual Conference and Exposition, Session 2257.

${ }^{12}$ Biernacki, J. J. and Wilson, C. , (1999) "Interdisciplinary Laboratory in Advanced Materials - A Team-Oriented Inquiry-Based Approach,” NSF Grant No. DUE-9950411.

${ }^{13}$ Biernacki, J. J. and Wilson, C., (2001), "Interdisciplinary Laboratory in Advanced Materials: A Team-Oriented Inquiry-Based Approach,” J. Eng. Ed., 1-4.

${ }^{14}$ Brannick, M. T., Sales, E., and Prince, C. (1997), “Team Performance Assessment and Measurement - Theory, Methods, and Applications,” Lawrence Erlbaum Associates, Inc., Mahwak, New Jersey, ISBN 0-8058-1638-0, p. 371.

${ }^{15}$ Mellacheruvu, P. M. (2005), "Electrical, Nonlinear Field and Pulsed Frequency-based Modeling of Electric Field Flow Fractionation,” MS Thesis, TTU (co-advisors: S. Mahajan (ECE) and J. J. Biernacki (CHE)).

${ }^{16}$ Watada, R. R. (2004), "Fabrication and Preliminary Dharacterization of MEMS-based Carbon Monoxide Sensors,” MS Thesis, TTU (advisor: J. J. Biernacki (ECE)).

${ }^{17}$ Vyas, N. (2004), “Characterization and Modelling of Micro Electrical Field Flow Fractionation Device,” MS Thesis, TTU (advisor: J. J. Biernacki (ECE)). 
${ }^{18}$ Biernacki, J. J., Mellacheruvu, P. M., and Mahajan, S., (2008), “Poisson’s Effects in Electrical Field Flow Fractionation,” J. Separation Sci., 31(12), 2219-2230.

${ }^{19}$ Biernacki, J. J., Mellacheruvu, P. M., and Mahajan, S., (2006), “An Electric Circuit Model for Electric Field Flow Fractionation,” Analytical Chemistry 78, 4998-5005.

${ }^{20}$ Biernacki, J. J., and Vyas, N., (2005), “A One-Dimensional Transient Model of Electric Field Flow Fractionation,” J. Electrophoresis, 26(1), 18-27.

${ }^{21}$ Biernacki, J. J., and Vyas, N., (2003), “Modeling of Micro-Electric Field Flow Fractionation,” Proceedings of the AIChE Annual Meeting.

${ }^{22}$ Biernacki, J. J., Fry, J. A., Gopisetti, H. V., and Watada, R. R., (2002), “Carbon Monoxide Microsensors,” Proceedings of the AIChE Annual Meeting.

${ }^{23}$ Clouse, R. W., “Long Lines, Short Tempers - Homeland Security,” Entrepreneurs in Action, Esprit, Vanderbilt University, Peabody College of Education and Human Development, Nashville, Tennessee.

${ }^{24}$ Biernacki, J. J., (2011), “Student teams, a simulation or a real team experience?” Proceedings of the American Society for Engineering Education.

${ }^{25}$ Lattuca, L. R., Voigt, L. J., and Fath, K. Q. (2004), “Does Inteterdisciplinarity Promote Learning? Theoretical Support and researchable questions,” The Review of Higher Education, 28(1), 23-48.

${ }^{26}$ Biernacki, J. J., (2005), “A Course-level Strategy for Continuous Improvement,” Chem. Eng. Ed., 39(3) 186-193. 